ARTICLE

\title{
Insulin enhances striatal dopamine release by activating cholinergic interneurons and thereby signals reward
}

Melissa A. Stouffer ${ }^{1,2}$, Catherine A. Woods ${ }^{3, \star}$, Jyoti C. Patel ${ }^{2, \star}$, Christian R. Lee ${ }^{2}$, Paul Witkovsky ${ }^{4}$, Li Bao ${ }^{1,2}$, Robert P. Machold ${ }^{5}$, Kymry T. Jones ${ }^{6}$, Soledad Cabeza de Vaca ${ }^{6}$, Maarten E.A. Reith ${ }^{6,7}$, Kenneth D. Carr ${ }^{6,7}$ \& Margaret E. Rice ${ }^{1,2}$

Insulin activates insulin receptors (InsRs) in the hypothalamus to signal satiety after a meal. However, the rising incidence of obesity, which results in chronically elevated insulin levels, implies that insulin may also act in brain centres that regulate motivation and reward. We report here that insulin can amplify action potential-dependent dopamine (DA) release in the nucleus accumbens (NAc) and caudate-putamen through an indirect mechanism that involves striatal cholinergic interneurons that express InsRs. Furthermore, two different chronic diet manipulations in rats, food restriction (FR) and an obesogenic (OB) diet, oppositely alter the sensitivity of striatal DA release to insulin, with enhanced responsiveness in $\mathrm{FR}$, but loss of responsiveness in $\mathrm{OB}$. Behavioural studies show that intact insulin levels in the NAc shell are necessary for acquisition of preference for the flavour of a paired glucose solution. Together, these data imply that striatal insulin signalling enhances DA release to influence food choices.

\footnotetext{
${ }^{1}$ Department of Neuroscience and Physiology, New York University School of Medicine, 550 First Avenue, New York, New York 10016, USA. ${ }^{2}$ Department of Neurosurgery, New York University School of Medicine, 550 First Avenue, New York, New York 10016, USA. ${ }^{3}$ Center for Neural Science, New York University, 4 Washington Place, New York, New York 10003, USA. ${ }^{4}$ Department of Ophthalmology, New York University School of Medicine, 550 First Avenue, New York, New York 10016, USA. ${ }^{5}$ Smilow Neuroscience Program, New York University School of Medicine, 550 First Avenue, New York, New York 10016 , USA. ${ }^{6}$ Department of Psychiatry, New York University School of Medicine, 550 First Avenue, New York, New York 10016, USA. 7 Department of Biochemistry and Molecular Pharmacology, New York University School of Medicine, 550 First Avenue, New York, New York 10016, USA. * These authors contributed equally to this work. Correspondence and requests for materials should be addressed to M.E.R. (email: margaret.rice@nyu.edu).
} 
$t$ is well established that a sustained increase in plasma insulin during and after a meal activates insulin receptors (InsRs) in the hypothalamus, which provides negative feedback to appetitive circuits that decreases further eating ${ }^{1-3}$. Brain insulin is derived primarily from pancreatic $\beta$ cells, with active transport from plasma to brain at the blood-brain barrier ${ }^{4-8}$, although there is increasing evidence for neuronal insulin synthesis and release, as well ${ }^{1,9}$. Notably, expression of InsRs is not confined to the hypothalamus, although the function of extra-hypothalamic InsRs remains unresolved ${ }^{1-3}$. Given the rising incidence of obesity and type II diabetes, in which circulating levels of insulin are perpetually elevated and brain insulin transport and receptor sensitivity are decreased $3,8,10,11$, it is critical to understand the function of insulin in brain regions that regulate motivation and reward. Brain regions of particular interest include the nucleus accumbens (NAc), which mediates the rewarding effects of both food and drugs ${ }^{12-13}$, and the caudate-putamen $(\mathrm{CPu})$, which plays a role in habit-based behaviours and craving ${ }^{13}$. InsRs are expressed throughout these regions, with the highest density occurring in the $\mathrm{NAc}^{3,14}$; InsRs are also expressed by dopamine (DA) neurons in the midbrain, including those in the ventral tegmental area (VTA) and substantia nigra pars compacta $(\mathrm{SNc})^{15}$. Brain insulin levels are proportional to plasma insulin concentrations and to body adiposity ${ }^{6-8}$, leading to the hypothesis that insulin might act at InsRs in these brain regions to influence food reward $3,16,17$.

Previous studies in striatal synaptosomes, heterologous cells, brain slices and in vivo have shown that insulin activation of InsRs leads to an increase in DA uptake by the DA transporter $(\mathrm{DAT})^{18-23}$. This process involves the PI3 kinase signalling pathway $^{19,20}$, and results in DAT insertion in the plasma membrane ${ }^{19}$. Circulating insulin levels dynamically modulate striatal DAT activity, with decreased DA uptake and DAT surface expression seen in animal models of diabetes and after food restriction $(\mathrm{FR})^{20,21}$. Insulin-dependent increases in DAT activity have been shown to decrease evoked extracellular DA concentration $\left([\mathrm{DA}]_{\mathrm{o}}\right)$ in the $\mathrm{VTA}^{23}$, reflecting a shift in the balance between DA release and uptake. Consistent with the established role of insulin in satiety, acute microinjection of insulin in the VTA can decrease food reward ${ }^{23,24}$, whereas mice lacking InsRs in VTA and SNc DA neurons show increased food intake and become obese ${ }^{25}$. Although insulin can induce longterm depression of excitatory input to VTA DA neurons ${ }^{24}$, again consistent with a role in satiety, insulin exposure can also increase DA neuron firing rate, possibly by decreasing DA release and autoreceptor-mediated inhibition $^{25}$. The net effect of insulin on striatal DA release is therefore hard to predict. Indeed, the results from studies of the influence of insulin on striatal DA release in ex vivo slices ${ }^{19}$ and the effect of local microinjection of insulin in the NAc on food reward ${ }^{26}$ appear to be contradictory. To resolve this, we evaluated axonal DA release and uptake in the intact microenvironment of the $\mathrm{NAc}$ and $\mathrm{CPu}$ in ex vivo striatal slices using fast-scan cyclic voltammetry (FCV), and determined the effects of insulin signalling in the NAc on reward behaviour in vivo.

Our studies show that the primary effect of insulin in NAc and $\mathrm{CPu}$ is to enhance $\mathrm{DA}$ release, despite a concurrent increase in DA uptake. This dynamic regulation of DA release involves an insulin-dependent increase in the excitability of striatal cholinergic interneurons (ChIs), which leads to enhanced DA release via activation of nicotinic acetylcholine (ACh) receptors (nAChRs). The influence of insulin on ChIs and on DA release is mediated by InsRs. Notably, the effect of insulin on DA release is amplified in slices from FR rats, but blunted in rats on an obesogenic (OB) diet. These data showing amplification of DA release in ex vivo slices by insulin lead to the prediction that insulin might act as a reward signal in vivo. Indeed, parallel behavioural studies demonstrate a role for insulin in the NAc shell in flavour-preference conditioning. Together, these findings indicate a new role for insulin as a reward signal that can influence food choice.

\section{Results}

Insulin acting at InsRs increases evoked striatal DA release. Initial examination of locally evoked $[\mathrm{DA}]_{\mathrm{o}}$ monitored with FCV in ex vivo striatal slices from rats with ad libitum (AL) access to food and water revealed the unexpected finding that acute application of insulin across a range of physiologically relevant concentrations $^{1,4}$ increased single-pulse-evoked [DA $]_{\mathrm{o}}$ (Fig. 1ac), with insulin $\mathrm{EC}_{50}$ values (the concentration at which the effect was half maximal) of 2-12 nM (Fig. 1b). Increased evoked [DA] was particularly surprising, given that this was accompanied by a significant increase in the maximal rate $\left(V_{\max }\right)$ for DAT-mediated uptake in each subregion (Table 1), which would lead to a competing decrease in evoked $[\mathrm{DA}]_{\mathrm{o}}$, as reported previously ${ }^{22-23}$ Instead, we found that evoked $[\mathrm{DA}]_{\mathrm{o}}$ was maximally amplified $20-55 \%$ by $30 \mathrm{nM}$ insulin; the region with the greatest proportional effect was the NAc shell, which is the striatal subregion with highest InsR expression ${ }^{1,14}$. Slices exposed to $30 \mathrm{nM}$ insulin under identical conditions showed no change in striatal DA content (Supplementary Fig. 1a), implying that insulin alters dynamic release regulation, rather than simply upregulating DA synthesis. Notably, the effect of insulin on evoked [DA $]_{o}$ was lost at supraphysiological concentrations $\geq 100 \mathrm{nM}$ (Fig. 1b). This was not a result of increased DAT activity overtaking release, as the effect of insulin on $V_{\max }$ was also lost at these concentrations (Table 1). Overall, these data show that in the intact striatal microenvironment, the predominant effect of insulin on evoked $[\mathrm{DA}]_{\mathrm{o}}$ is to increase release, despite a concurrent increase in DA uptake.

Because insulin can also act at insulin-like growth factor 1 receptors (IGF-1Rs), albeit at concentrations exceeding $100 \mathrm{nM}$ (ref. 1), we sought to confirm that the enhancing effect of insulin on evoked $[\mathrm{DA}]_{\mathrm{o}}$ was InsR dependent. This proved to be the case, as the effect was prevented by an intracellular InsR inhibitor, hydroxy-2-naphthalenylmethylphosphonic acid (HNMPA), and by an InsR antagonist, S961, but not by a selective inhibitor of IGF-1Rs, picropodophyllin ${ }^{24}$ (PPP; Fig. 1c,d and Supplementary Fig. 1b,c). We then examined the involvement of PI3 kinase, which initiates the signalling pathway responsible for insulindependent regulation of the $\mathrm{DAT}^{19}$. At a concentration of $1 \mu \mathrm{M}$, the P13K inhibitor LY249002 alone had no effect on peak-evoked $[\mathrm{DA}]_{\mathrm{o}}$ or $V_{\max }(n=29-76$ sites (NAc core) per drug, $P>0.05$, one-way analysis of variance (ANOVA); data not shown), yet prevented the effect of insulin on evoked $[\mathrm{DA}]_{\mathrm{o}}$ in all striatal subregions (Fig. 1d and Supplementary Fig. 1b,c).

Localization of InsRs on DA axons and ChIs. The observed increase in $V_{\max }$ for DA uptake with physiological levels of insulin implies the presence of InsRs on DA axons, as do previous results in various striatal preparations ${ }^{18-22}$. Although functional expression of InsRs on midbrain DA neurons has been demonstrated $^{15,23-25}$, InsR expression on striatal DA axons has not been reported. We addressed this using immunohistochemistry. Dense InsR immunoreactivity throughout the striatum limited quantitative assessment of InsR localization on DA axons, which were identified by immunoreactivity for a DA-synthesizing enzyme, tyrosine hydroxylase (TH). We therefore adopted a previously reported protocol ${ }^{27}$, which involved counting InsR puncta that overlapped with $\mathrm{TH}+$ profiles in normal image view and counting again after the InsR 


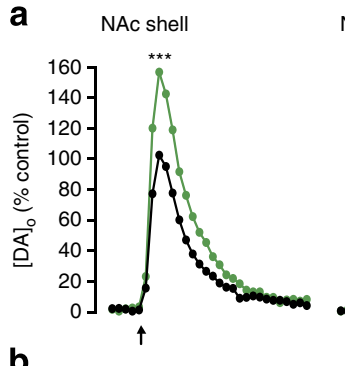

b

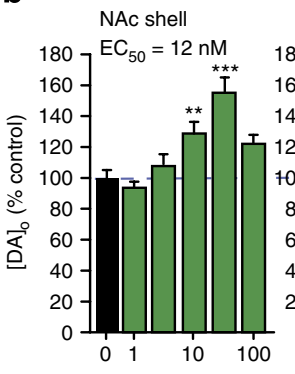

NAc core

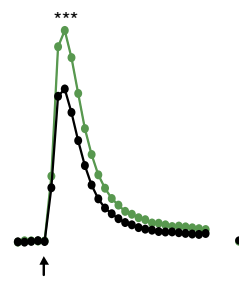

NAc core

$\mathrm{EC}_{50}=5 \mathrm{nM}$
$\mathrm{CPu}$

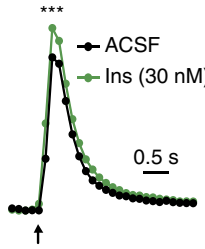

$\mathrm{CPu}$

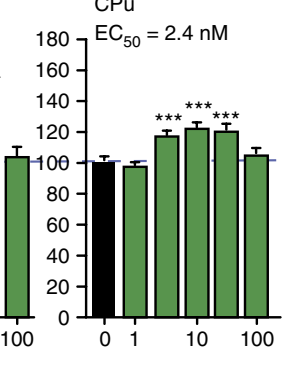

C
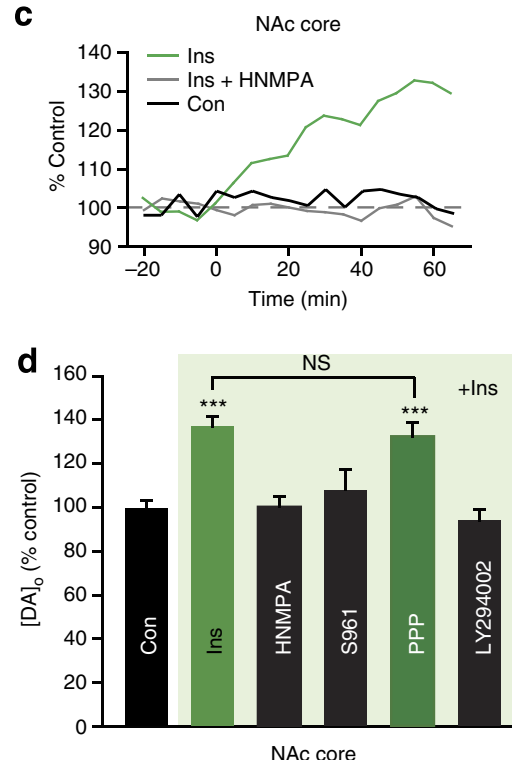

Figure 1 | Insulin-dependent increases in evoked [DA] require InsRs and PI3K. (a) Average single-pulse-evoked [DA] in NAc shell, NAc core and CPu before and after insulin (Ins) illustrated for $30 \mathrm{nM}$; error bars omitted, but see (b); arrows indicate time of stimulus. Insulin increased evoked [DA]。 in shell (by $55 \pm 10 \%$ ), core (by $37 \pm 5 \%)$ and $\mathrm{CPu}$ (by $20 \pm 4 \%$ ) $\left.{ }^{\star \star \star} P<0.001\right)$. (b) Effect of insulin was concentration dependent across a physiological range $(1-30 \mathrm{nM})$ in shell $\left(n=22-24, F_{5,133}=14.471, P<0.001\right)$, core $\left(n=36-76, F_{5,308}=16.318, P<0.001\right)$ and $\mathrm{CPu}\left(n=30-62, F_{5,253}=13.763, P<0.001\right)$, but lost at $\geq 100 \mathrm{nM}$. (c) Representative recordings of peak-evoked [DA]。 versus time at a single site in the NAc core in the absence of drug application (Con), during application of insulin $(30 \mathrm{nM})$ or when insulin was applied in the presence of an InsR inhibitor HNMPA ( $5 \mu M)$. (d) Average peak-evoked $[D A]_{0}$ data showing prevention of the effect of insulin $(30 \mathrm{nM})$ by HNMPA, InsR antagonist S961 $(1 \mu \mathrm{M})$ and PI3K inhibitor LY294002 $(1 \mu \mathrm{M})$, but not by IGF-1R inhibitor PPP $(1 \mu \mathrm{M})(n=29-76 ; P>0.9$ versus insulin alone). For Fig. 1a-d, $n=$ number of sites per subregion from 3-6 rats for each drug or insulin concentration; one-way ANOVA, Tukey honest significance test (HSD). See Supplementary Fig. 1b,c for NAc shell and CPu data.

Table 1 | Insulin at physiological concentrations $(30 \mathrm{nM})$ increases $V_{\max }$ for DAT-mediated uptake in striatal slices.

$V_{\max }\left(\mu M s^{-1}\right)$

\begin{tabular}{|c|c|c|c|c|c|c|}
\hline & Control & $n$ & Insulin (30 nM) & $n$ & Insulin (100 nM) & $n$ \\
\hline NAc shell & $\begin{array}{l}0.88 \pm 0.04 \\
R^{2}=0.9125\end{array}$ & 25 & $\begin{array}{l}1.09 \pm 0.09^{\star} \\
R^{2}=0.9392\end{array}$ & 21 & $\begin{array}{l}0.82 \pm 0.05 \\
R^{2}=0.9014\end{array}$ & 23 \\
\hline NAc core & $\begin{array}{l}2.06 \pm 0.07 \\
R^{2}=0.9937\end{array}$ & 73 & $\begin{array}{l}2.32 \pm 0.08^{\star} \\
R^{2}=0.9929\end{array}$ & 61 & $\begin{array}{l}2.20 \pm 0.08 \\
R^{2}=0.9912\end{array}$ & 36 \\
\hline $\mathrm{CPu}$ & $\begin{array}{l}3.23 \pm 0.08 \\
R^{2}=0.9902\end{array}$ & 62 & $\begin{array}{l}3.63 \pm 0.15^{\star} \\
R^{2}=0.9924\end{array}$ & 40 & $\begin{array}{l}3.39 \pm 0.09 \\
R^{2}=0.9946\end{array}$ & 29 \\
\hline
\end{tabular}

$V_{\max }$ values for DAT-mediated uptake after evoked striatal DA release were determined from evoked $[D A]_{0}$ records using a fixed $K_{m}$ of $0.2 \mu M$ for all regions and conditions. Data are means \pm s.e.m, $n$, number of sites, $R^{2}$ indicates goodness of fit $\left({ }^{\star} P<0.05\right.$ versus control, one-way ANOVA followed by Dunnett's post hoc test).

image only was rotated by $90^{\circ}$. If apparent overlap of InsR and $\mathrm{TH}+$ profiles were nonspecific, this procedure should give statistically similar counts whether normal or $90^{\circ}$ out of phase. However, this analysis showed a decrease in the overlap of InsR puncta with $\mathrm{TH}+$ profiles of $14 \pm 9 \% \quad(n=42$ fields, $P<0.01$, paired two-tailed $t$-test; data not shown), confirming InsR presence on DA axons. More intriguingly, however, InsR immunolabelling of the striatum revealed distinct InsR expression on large cell bodies that were identified as striatal ChIs by co-immunolabelling for choline acetyltransferase (ChAT), the primary enzyme required for ACh synthesis. Using electrophysiological criteria ${ }^{28}$ to identify ChIs in preliminary whole-cell-recording studies, several neurons were filled with biocytin and then processed for immunohistochemistry; all of these (4/4) were immunopositive for both InsR and ChAT (Fig. 2a). Subsequent evaluation of InsR and ChAT colocalization in the NAc confirmed that virtually all ChAT + neurons expressed InsR (96\%; $n=27 / 28$ neurons in four sections from two rats).
Insulin increases ChI excitability. To test the functionality of InsRs on striatal ChIs, we examined the effect of insulin on ChI excitability using whole-cell current-clamp recording. ChI excitability was assessed using a series of 3-s depolarizing current pulses to elicit a train of action potentials that reliably exhibited spike frequency adaptation (Fig. 2b), often with loss of spiking by the end of the current pulse. Strikingly, insulin $(30 \mathrm{nM})$ attenuated spike frequency adaptation, resulting in a progressive increase in action potential number over time (Fig. 2c), with a maximum increase (Fig. 2d,e) typically seen between 20 and $50 \mathrm{~min}$ of insulin exposure. In the absence of insulin, control ChIs showed no change in the number of evoked action potentials $(P>0.05$, paired two-tailed $t$-test; data not shown); when compared with control neurons monitored over the same time interval, neurons exposed to insulin showed a significantly greater change in the number of evoked action potentials (control $n=12$ stimulus pairs from four neurons, insulin $n=21$ stimulus pairs from seven neurons, $F_{1,25}=5.63, P<0.05$, mixed-measures twoway ANOVA; data not shown). The effect of insulin on 
a
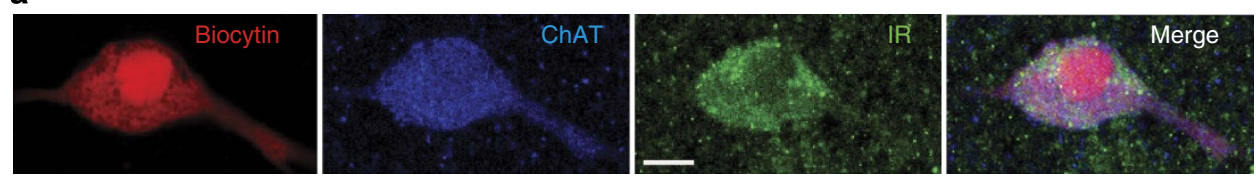

b

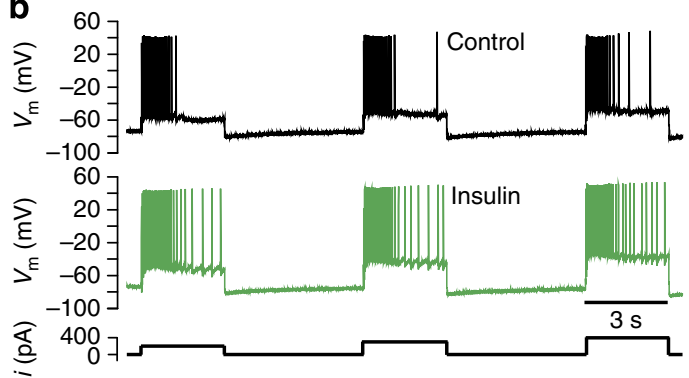

C

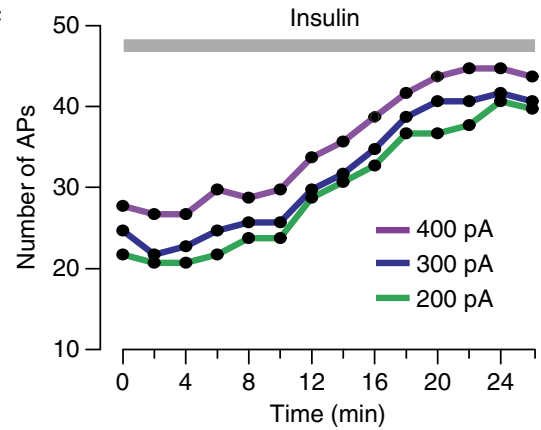

d

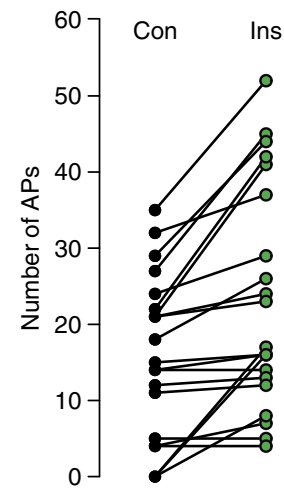

e
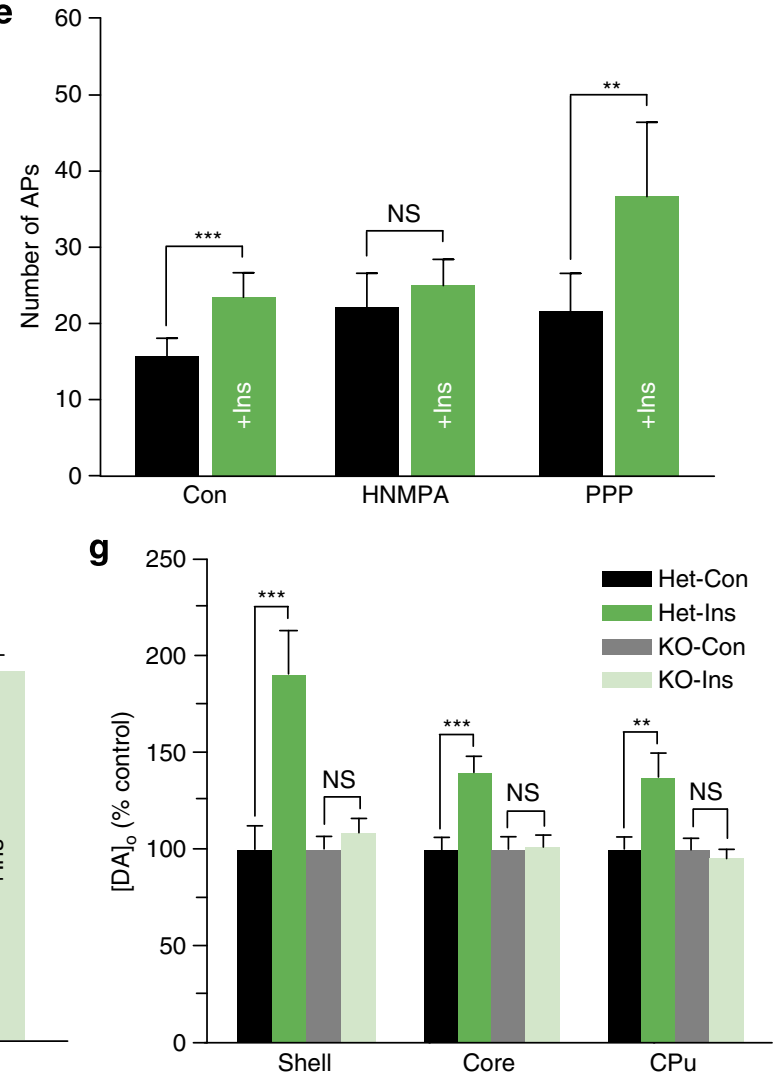

Figure 2 | Insulin-dependent regulation of striatal DA release requires ACh from Chls. (a) Chl filled with biocytin, then immunolabelled for ChAT, and InsR (representative of 4/4 biocytin-filled Chls); merged image shows co-localization; scale bar, $10 \mu \mathrm{m}$. (b-e) Response of striatal Chls to a series of depolarizing current pulses (3-s duration; 200, 300 and 400 pA; 120-s intervals) before and after insulin (30 nM). (b) Spike frequency adaptation in a Chl (upper) is seen in loss of action potential (AP) discharge during current injection, whereas spiking persists throughout the current pulse in insulin (lower); complete data set shown in d. (c) Representative time course of the insulin-induced increase in AP number with each current step for the Chl in $\mathbf{b}$.

(d) Summary of AP number during current pulses delivered before and at the peak effect of insulin exposure $(n=21$ paired stimulations, 7 neurons, 5 rats)

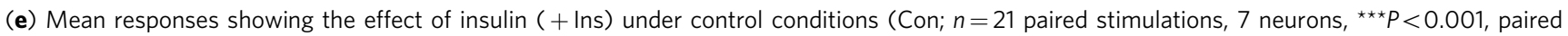
two-tailed $t$-test), in the presence of HNMPA $(5 \mu \mathrm{M})(n=12$ paired stimulations, 4 neurons, 4 rats, $P>0.05$, paired two-tailed $t$-test), and in the presence of PPP $(1 \mu \mathrm{M})\left(n=18\right.$ paired stimulations, 6 neurons, 6 rats, ${ }^{\star \star} P<0.01$, Wilcoxon matched pair signed rank test). (f) Average single-pulse-evoked [DA] in NAc core before and after insulin $(30 \mathrm{nM})$ in mecamylamine $(\mathrm{Mec} ; 5 \mu \mathrm{M})$ or $\mathrm{DH} \beta \mathrm{E}(1 \mu \mathrm{M})$ normalized to $100 \%$ peak control ( $n=20-40$ sites per subregion per condition from 3-4 rats, $P>0.05$ versus control, unpaired $t$-test). (g) Average single-pulse-evoked [DA]。 in forebrain slices from heterozygous control (Het) and ChAT KO mice before and after insulin (30 nM), normalized to 100\% peak control. Insulin increased evoked [DA]。 in heterozygous mice by $190 \pm 23 \%$ in NAc shell, $140 \pm 8 \%$ in NAc core and $137 \pm 12 \%$ in CPu ( $n=15-25$ sites per subregion from 3-4 mice per genotype, ${ }^{\star \star} P<0.01,{ }^{\star \star} P<0.001$ versus control unpaired $t$-test $)$, but had no effect on evoked $[D A]_{0}$ in any striatal subregion of $C h A T$ KO mice $(P>0.1)$. 
increasing action potential number was prevented by HNMPA but not by the IGF-1R selective inhibitor PPP (Fig. 2e), demonstrating that increased ChI excitability by insulin was InsR mediated.

Insulin enhancement of evoked [DA $]_{\mathrm{o}}$ requires nAChRs and ACh. Previous studies have shown that ChIs and ACh potently regulate striatal DA release via nAChRs on DA axons ${ }^{29-34}$. Abundant InsR expression on ChIs and the enhancement in ChI excitability seen with acute insulin exposure suggested that these neurons might be novel targets for insulin that could lead to enhanced DA release. To test this, we examined the effect of insulin in the presence of mecamylamine, a non-selective nAChR antagonist, or dihydro- $\beta$-erythroidine $(\mathrm{DH} \beta \mathrm{E})$, a selective antagonist for $\beta 2$ subunit-containing $\left(\beta 2^{*}\right) \mathrm{nAChRs}$ that are enriched on DA axons $^{35}$. Evoked $[\mathrm{DA}]_{\mathrm{o}}$ was readily detected in the presence of these antagonists, even though both drugs decreased the amplitude of single-pulse-evoked $[\mathrm{DA}]_{\mathrm{o}}$ (for example, by $13-26 \%$ in NAc core), as reported previously ${ }^{29-32}$. In support of a role for ACh and nAChRs, the effect of insulin on evoked $[\mathrm{DA}]_{\mathrm{o}}$ was prevented by either mecamylamine or $\mathrm{DH} \beta \mathrm{E}$ (Fig. 2f). To confirm the involvement of striatal ACh signalling in insulin-enhanced DA release, we examined the effect of insulin in ex vivo striatal slices from mice in which ChAT expression was genetically ablated in forebrain structures (forebrain ChAT KO mice), including striatum ${ }^{32}$. Although ChIs are intact in these mice, ACh synthesis is abolished, which leads to decreased, but still readily detectable single-pulse-evoked $[\mathrm{DA}]_{\mathrm{o}}$, as described previously $^{32}$. In control heterozygous littermates, insulin $(30 \mathrm{nM})$ increased evoked [DA] in NAc shell and core and in CPu by 37$90 \%$ (Fig. 2g), exceeding the amplification seen in rat striatum (for example, Fig. 1). However, the effect of insulin on evoked $[\mathrm{DA}]_{\mathrm{o}}$ was absent throughout the striatal complex in forebrain ChAT KO mice, demonstrating that insulin-mediated enhancement of DA release requires striatal $\mathrm{ACh}$, but not coreleased transmitters from ChIs, such as glutamate ${ }^{36}$.

The influence of insulin on evoked $[\mathrm{DA}]_{\mathrm{o}}$ is diet dependent. Plasma and brain insulin concentrations are proportional to body adiposity $^{6-8}$, and could lead to compensatory changes in brain sensitivity to insulin. We therefore tested the hypothesis that diet influences the ability of insulin to promote DA release, using striatal slices from rats maintained on either a chronic FR or OB diet versus AL controls. As expected, plasma insulin levels were correlated with body weight, with lower insulin in FR than in $\mathrm{AL}$ or $\mathrm{OB}$ rats (Fig. 3a and Table 2). Despite these differences in circulating insulin, peak-evoked $[\mathrm{DA}]_{\mathrm{o}}$ in NAc shell and core, and $\mathrm{CPu}$ was significantly lower in ex vivo striatal slices from both diet groups compared with AL (Fig. 3b and Supplementary Fig. 2 a,b), implying that factors in addition to insulin govern absolute evoked $[\mathrm{DA}]_{\mathrm{o}}$. Striatal DA content did not differ among diet groups, indicating a change in release regulation rather than in DA synthesis (Supplementary Fig. 2c). Consistent with a change in dynamic regulation, the sensitivity of striatal DA release to insulin was markedly diet dependent. In FR rats, insulin concentrations $\leq 1 \mathrm{nM}$, which had no effect in AL (Fig. 1b), increased evoked $[\mathrm{DA}]_{\mathrm{o}}$ (Fig. 3c), reflecting increased insulin sensitivity, with $\mathrm{EC}_{50}$ values in FR striatum $(0.4-0.6 \mathrm{nM})$ that were approximately an order of magnitude lower that in $\mathrm{AL}$ (compare Figs $1 \mathrm{~b}$ and $3 \mathrm{c}$ ). In striking contrast, the effect of insulin was lost in $\mathrm{OB}$ striatum; even $30 \mathrm{nM}$ insulin, which had a maximal effect in AL striatum (Fig. 1b), had no effect in $\mathrm{OB}$ (Fig. 3c).

These data imply an inverse relationship between striatal InsR sensitivity and body adiposity. Alternatively, however, these diet- dependent differences might reflect altered nAChR sensitivity. We therefore determined the concentration response to nicotine in NAc core from each diet group. Nicotine causes nAChR desensitization, which can be quantified by comparing the ratio of $[D A]_{o}$ evoked by a brief train of five pulses at $100 \mathrm{~Hz}$ to singlepulse-evoked $[\mathrm{DA}]_{\mathrm{o}}$ (5 $\mathrm{p}: 1 \mathrm{p}$ ratio) as an index of $\mathrm{nAChR}$ activation/desensitization $^{30,31}$. Using this approach, we found no differences among diet groups in nAChR sensitivity in the NAc core (Supplementary Fig. 3a-c). Furthermore, control 5 p:1 $\mathrm{p}$ ratio did not differ among diet groups in NAc core (Supplementary Fig. 3d) or $\mathrm{CPu}$ (not illustrated), implying that diet does not alter nAChR-dependent DA release regulation. Thus, striatal InsR sensitivity appears to be enhanced in FR versus $\mathrm{AL}$ rats, but absent in $\mathrm{OB}$ rats, with loss of regulation of striatal DA release at physiological concentrations of insulin.

NAc shell insulin modulates conditioned flavour preference. Food preferences are generated by both pre- and post-ingestive factors; the mechanisms for each are not completely resolved, but current evidence implicates NAc DA signalling in both ${ }^{37,38}$. Given that plasma and cerebrospinal fluid (CSF) insulin levels rise rapidly after peripheral glucose elevation ${ }^{6}$, and that an increase in insulin in the striatum can be detected within 5 min of plasma insulin elevation ${ }^{7}$, it is logical to hypothesize that peripheral insulin release during a meal could enhance NAc DA release and contribute to post-ingestive reward mechanisms. We adapted a previously described flavour-preference protocol ${ }^{37}$ with saccharin-sweetened glucose solutions in rats to test the hypothesis that blocking the effect of endogenous insulin through local application of an insulin antibody (InsAb) in the NAc would decrease preference for the paired flavour. The efficacy of the InsAb in blocking the effects of insulin was tested in an in vitro assay of DA uptake into striatal synaptosomes. Insulin $(30 \mathrm{nM})$ caused a significant increase in $V_{\max }$ in synaptosomes from NAc or $\mathrm{CPu}$ (Supplementary Fig. 4), consistent with our $V_{\max }$ data from striatal slices (Table 1 ) and with previous studies ${ }^{18-23}$. In the absence of insulin, neither InsAb nor a control antibody immunoglobulin G (IgG) altered the $V_{\max }$ for DA uptake versus control. In the presence of IgG, insulin still caused a significant increase in $V_{\max }$; however, the effect of insulin on $V_{\max }$ was lost in the presence of InsAb (Supplementary Fig. 4).

To minimize tissue damage and preserve sensitivity of the tissue target, two groups of subjects were tested in which we alternated intra-NAc microinjection with a mock microinjection procedure, rather than using a single group of subjects and pairing one flavoured solution with InsAb and another with vehicle. Consequently, during one-bottle-conditioning sessions, the experimental group received InsAb microinjections paired with one of two flavours, and on alternating sessions, mock microinjections paired with the other flavour (Fig. 4a, left). The control group received mock microinjections alternated with microinjections of either phosphate-buffered saline (PBS) or IgG. Both flavoured solutions contained glucose during conditioning. No differential preference between flavours was expected in the control-microinjected group, whereas preference was expected to shift toward the mock microinjection-paired flavour in the InsAb-microinjected group.

During the one-bottle conditioning sessions, InsAb microinjection significantly decreased consumption compared with vehicle during the third and fourth infusions (Fig. 4b). By contrast, both groups consumed the same volume of solution during all four mock injection sessions $\left(F_{3,111}=0.127, P>0.05\right.$, mixed two-way ANOVA) (Fig. 4b). After a total of eight conditioning sessions, flavour preference was assessed in a twobottle test in which rats had access to both flavoured solutions 

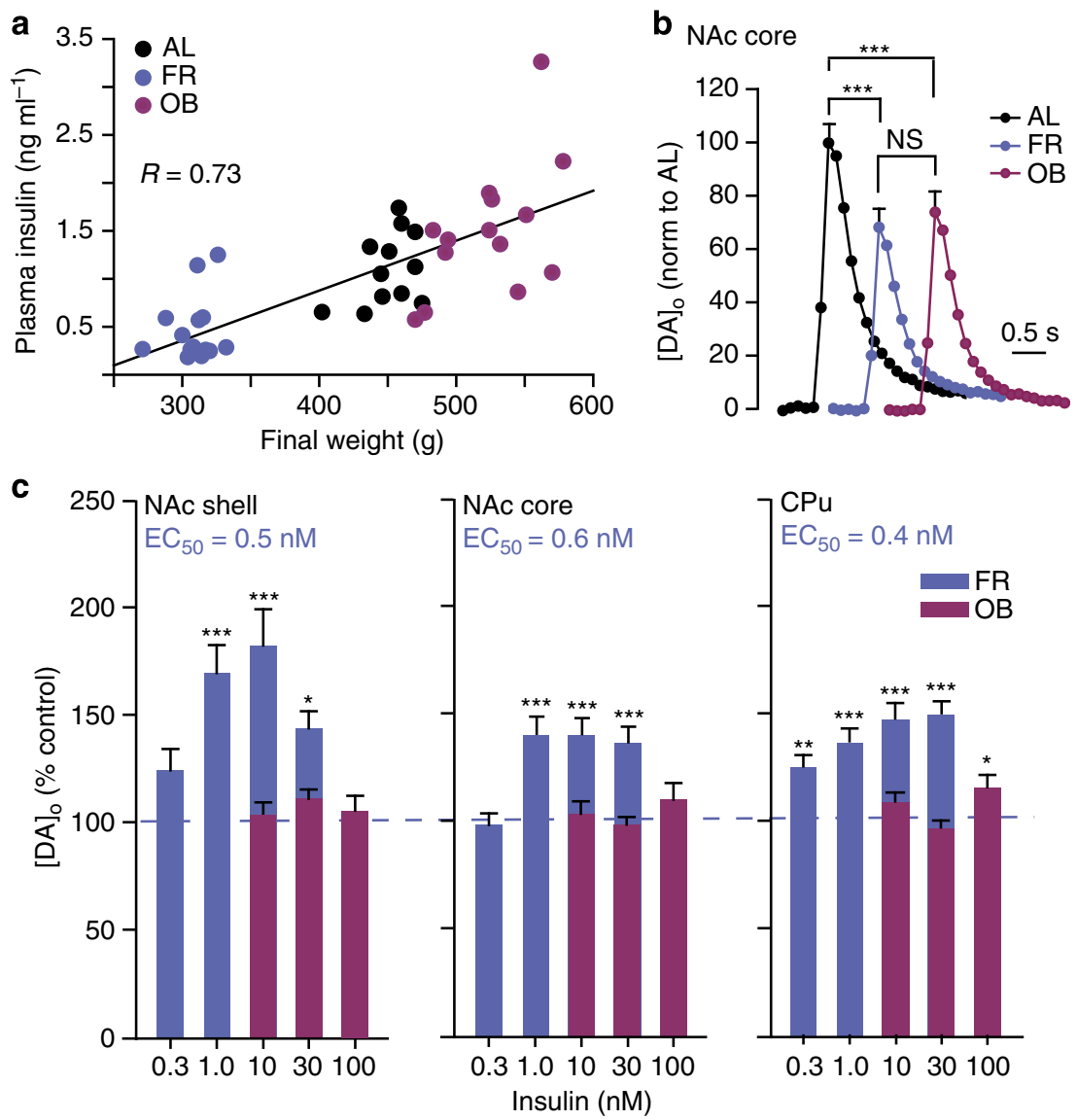

Figure 3 | Insulin-induced increases in evoked [DA] are enhanced by FR and lost in OB. (a) Plasma insulin concentration is positively correlated with body weight across feeding groups $(R=0.76)$. (b) Average single-pulse-evoked $[\mathrm{DA}]_{\mathrm{o}}$ in NAc core (see Supplementary Fig. 2a,b for NAc shell and CPu) was lower in FR $(38 \pm 4 \%)$ and $\mathrm{OB}(25 \pm 4 \%)$ versus $\mathrm{AL}\left(n=50-60\right.$ sites from 5-6 rats per diet group, $F_{2,156}=23.337$, one-way ANOVA, Tukey HSD; $\left.{ }^{\star \star \star} P<0.001\right)$; OB versus FR $(P<0.08)$. (c) Sensitivity of evoked $[D A]_{0}$ to insulin was enhanced in FR, but lost in OB $(n=21-49$ sites per subregion per concentration from 2-4 rats per diet group, one-way ANOVA, Tukey HSD), with greater sensitivity in FR versus AL rats in all subregions $(P<0.001$ for each region; two-way ANOVA; $C P$ : $F_{(\text {conc } \times \text { diet; 3,286) }}=10.253$; core: $F_{(\text {conc } \times \text { diet; 3,353) }}=6.166$; shell: $\left.F_{(\text {conc } \times \text { diet; } 3,195)}=10.735\right)$.

Table 2 | Final body weight, weight change, plasma insulin and blood glucose values of rats on AL, OB or FR diet.

\begin{tabular}{|c|c|c|c|c|}
\hline Diet group & Final body weight (g) & Per cent weight gain or loss & Plasma insulin $\left(\mathrm{ng} \mathrm{ml}^{-1}\right)$ & Blood glucose $\left(\mathrm{mg} \mathrm{dl}^{-1}\right)$ \\
\hline$A L$ & $451 \pm 5$ & $23.6 \pm 1.8$ & $1.11 \pm 0.11$ & $125 \pm 4$ \\
\hline OB & $523 \pm 10^{\star \star \star}$ & $36.2 \pm 1.9^{\star \star \star}$ & $1.51 \pm 0.18$ & $125 \pm 6$ \\
\hline FR & $304 \pm 3^{\star \star \star}$ & $-21.9 \pm 0.3^{\star \star \star}$ & $0.44 \pm 0.08^{\star \star \star}$ & $117 \pm 5$ \\
\hline
\end{tabular}

simultaneously (Fig. 4a). Statistical analysis revealed a significant interaction between flavour and the microinjection treatment received during conditioning (Fig. 4c). The InsAb group consumed significantly less of the InsAb-paired flavour compared with the mock-paired flavour (Fig. 4c), whereas the vehicle group showed no flavour preference (Fig. 4c), implying that intact insulin signalling contributed to selection of a sweet caloric solution. Compared with vehicle, InsAb-microinjected rats drank significantly less of the infusion-paired flavour and significantly more of the mock-injection-paired flavour (Fig. 4c). Microinjection of $\operatorname{IgG}(t(9)=0.792$. $P>0.05$, protected $t$-tests $)$ or PBS $(t(9)=0.442 . P>0.05$, protected $t$-tests) had no effect on flavour preference (data not shown), arguing against the possibility that a nonspecific effect of InsAb microinjection decreased consumption or flavour preference. It should also be noted that the preference of the InsAb group at test is not a preference for the less novel flavour, as there was no interaction between session and session type (actual infusion versus mock infusion) for the InsAb group $\left(F_{3,54}=1.584, P>0.05\right.$, two-way ANOVA). That is, the Ins $A b$ group did not consume more of the mock-infusion-paired flavour relative to the InsAb infusion-paired flavour; rather, differences between treatment groups only emerged during infusion-conditioning sessions. Overall, these data indicate that insulin in the NAc plays a role in reinforcement of preference for a flavour that signals a glycaemic load.

\section{Discussion}

We report here that insulin amplifies striatal DA release in a nAChR-dependent manner by modulating ChI excitability via InsRs. Our results imply that insulin can serve as a reward signal, in addition to its established role in signalling satiety. Notably, the effect of insulin on DA release is modulated by diet, with markedly increased sensitivity to insulin after FR, but a complete 
a

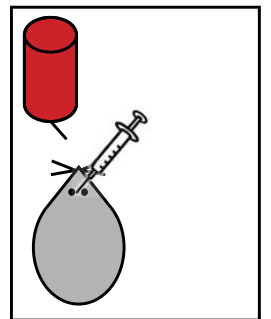

Day 1

InsAb or control
Two-bottle test

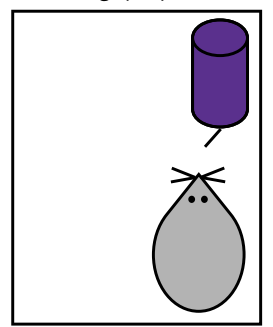

Day 2

Mock infusion

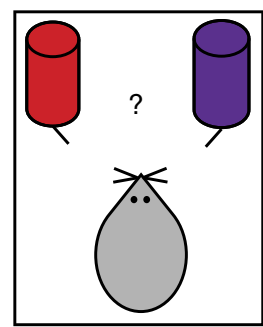

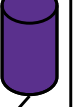

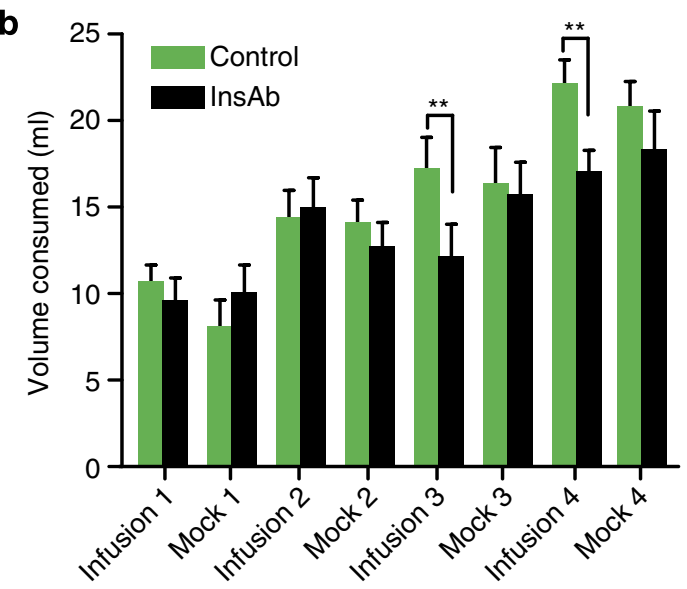

C

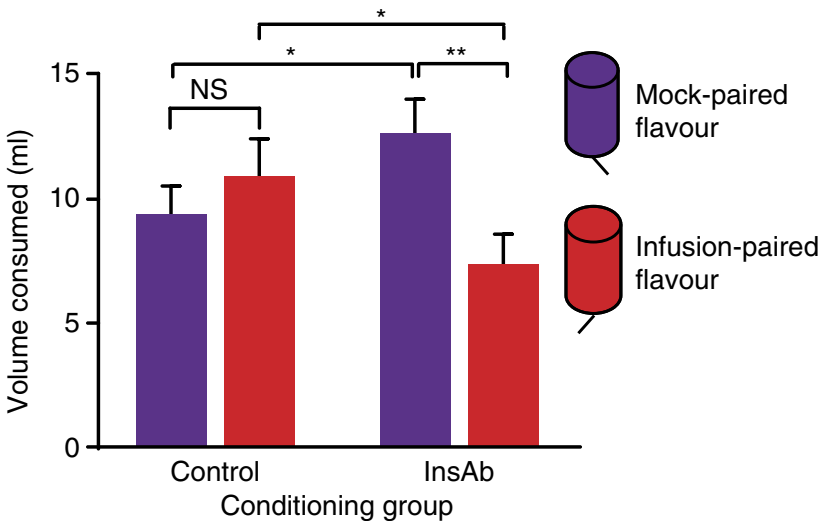

Figure 4 | InsAb microinjection into the NAc shell decreases flavour preference. (a) Diagram illustrating one-bottle conditioning (left) and the two-bottle test (right). (b) Volume consumed ( $\mathrm{ml}$ ) during one-bottleconditioning sessions. There was a significant interaction between infusionconditioning session and microinjection treatment $(n=19-20$ rats per group, $F_{(3,111)}=3.088, P<0.05,2 \times 4$ mixed ANOVA with repeated measures on infusion-conditioning session). InsAb microinjection significantly decreased consumption compared with control during the third $\left(t(40)=3.026,{ }^{\star \star} P<0.01\right)$ and fourth $\left(t(40)=3.052,{ }^{\star \star} P<0.01\right.$, protected one-tailed $t$-tests) infusions. Mock injections had no effect on consumption in either group $\left(F_{3,111}=1.110,2 \times 4\right.$ mixed ANOVA with repeated measures on mock conditioning session). (c) Volume consumed during two-bottle flavour-preference test. There was a significant interaction between flavour and microinjection treatment during conditioning $\left(F_{1,37}=5.36, P<0.05\right.$, two-way mixed ANOVA with repeated measures on flavour). The Ins Ab group consumed significantly less of the InsAb-paired flavour compared with the mock-paired flavour $\left(t(18)=2.82,{ }^{\star} * P<0.01\right.$, protected one-tailed $t$-test); the control group showed no flavour preference $(t(19)=0.803$, $P>0.05$, protected $t$-test). Comparing groups, Ins $A b$ rats drank significantly less of the infusion-paired flavour $\left(t(40)=1.96,{ }^{\star} P<0.05\right)$ and significantly more of the mock-paired flavour $\left(t(40)=1.77,{ }^{\star} P<0.05\right.$, protected one-tailed $t$-test) than controls. loss of insulin-enhanced regulation on an $\mathrm{OB}$ diet. These changes appear to reflect changes in InsR sensitivity that are inversely related to circulating insulin levels, given that plasma insulin levels were found to be diet dependent, but nAChR sensitivity was not. Finally, our flavour-preference studies in behaving animals imply that insulin signalling in the NAc shell influences food preference, which not only implicates insulin in food-related learning but also confirms its role as a reward signal.

Net $[\mathrm{DA}]_{\mathrm{o}}$ reflects the balance between DA release and DA uptake via the DAT. Previous evidence showing that insulin can regulate DAT activity ${ }^{18-23}$ led to the prediction that an increase in insulin should cause a net decrease in evoked $[\mathrm{DA}]_{\mathrm{o}}$ via increased DA uptake. However, we found that in the striatum, the effect of insulin is more complex than this. Although insulin exposure did increase $V_{\max }$ for the DAT, the primary effect of insulin was on DA release, not on DA uptake, with a consistent increase in evoked $[\mathrm{DA}]_{\mathrm{o}}$ across a physiological range of insulin concentrations in NAc shell and core and in $\mathrm{CPu}$. Although the increase in evoked $[\mathrm{DA}]_{\mathrm{o}}$ did revert to control levels at a supraphysiological concentration of $100 \mathrm{nM}, V_{\max }$ was also unchanged from control, eliminating a predominant effect on the DAT as an explanation. Instead, loss of the effect on uptake as well as release implicates desensitization of InsRs or downregulation of downstream signalling pathways at high insulin concentrations. Indeed, InsRs undergo rapid endocytosis and degradation after insulin binding in peripheral tissues ${ }^{1}$, with emerging evidence for loss of neuronal InsR sensitivity after short-term exposure to high levels of insulin or high-calorie diets $^{10,11,39}$.

The dominant effect of insulin to enhance striatal DA release reported here contrasts with the results of two other recent ex vivo slice studies. In the first, insulin caused a decrease in electrically evoked overflow of $\left[{ }^{3} \mathrm{H}\right] \mathrm{DA}$ from striatal slices, although increased $\left[{ }^{3} \mathrm{H}\right] \mathrm{DA}$ overflow was detected when the DAT was inhibited ${ }^{22}$. Given that released $\left[{ }^{3} \mathrm{H}\right] \mathrm{DA}$ must escape DAT-mediated uptake throughout the tissue to be detected in the superfusing solution, this protocol is especially sensitive to DAT regulation. Our results showing that insulin enhances DA release via ChIs and nAChR activation, in addition to enhancing DATmediated uptake, would explain the seemingly paradoxical increase in insulin-enhanced $\left[{ }^{3} \mathrm{H}\right] \mathrm{DA}$ overflow seen when competing effects on the DAT were blocked ${ }^{22}$. The second study used FCV for direct detection of somatodendritic DA release in the VTA, but also found a predominant effect of insulin on DA uptake, reflected in decreased evoked [DA $]_{\mathrm{o}}$ (ref. 23). Differences in a number of factors, from local microcircuitry to somatodendritic versus axonal DA release mechanisms ${ }^{40}$, could contribute to this regional difference. As discussed further below, however, regionally dependent roles of insulin are likely to be complementary, rather than contradictory.

Previously, any role of insulin-dependent regulation of DA signalling had been assumed to be mediated by direct activation of InsRs on DA neurons. We show here that InsRs are also expressed on striatal ChIs, and that insulin modulates ChI excitability to amplify striatal DA release, which may play a pivotal role in the influence of insulin on diet. Striatal ChIs receive projections from neurons of the intralaminar nuclei of the thalamus, which exhibit burst firing in response to salient sensory stimuli and help drive burst-pause spiking patterns in ChIs that are important in directing attention, reinforcement and associative learning ${ }^{41}$. Therefore, the action of insulin at InsRs on striatal ChIs could enhance the effect of sensory food cues on striatal responsiveness to thalamic firing, contributing to increased perception of the reward value of an ingested meal. Direct promotion of striatal DA release by ChI activation has led to the suggestion that factors that stimulate ChIs will have a privileged 
role as triggers of DA release $\mathrm{s}^{33}$. Our data provide the first supporting evidence for this, with insulin-enhanced ChI excitability and ACh signalling driving dynamic increases in DA release.

Elevated DA release in the presence of insulin also argues against an enhancement in ACh signalling to an extent that causes nAChR desensitization or muscarinic ACh receptor (mAChR) activation, either of which can suppress single-pulseevoked $[\mathrm{DA}]_{\mathrm{o}}$ (refs 29-31,42). Thus, the mechanisms reported here are distinct from ACh activation of mAChRs, which has been associated with aversion and satiety ${ }^{43}$.

Single-pulse-evoked $[\mathrm{DA}]_{\mathrm{o}}$ was lower in both FR and $\mathrm{OB}$ rats than in AL rats; although these results are in consonance with previous reports ${ }^{44-46}$, our studies provide the first systematic comparison of three striatal subregions in the two diet groups over a constant time frame. The mechanisms underlying dietdependent changes in DA release have not been elucidated, and are beyond the scope of the present studies. However, given that plasma insulin levels are oppositely altered by FR and OB diets, it is unlikely that decreased evoked $[\mathrm{DA}]_{\mathrm{o}}$ in both groups is a consequence of diet-dependent insulin levels.

On the other hand, changes in InsR sensitivity with diet and consequent diet-dependent plasma insulin levels provide the most likely explanation for increased sensitivity to insulin in FR and loss of responsiveness to insulin in OB. There was no evidence for the alternative explanation of altered $\mathrm{nAChR}$ sensitivity in either FR or OB rats versus AL. Although our findings are among the first to indicate increased striatal InsR sensitivity with $\mathrm{FR}^{18}$, weight loss can be accompanied by decreased insulin levels in $\mathrm{CSF}^{7}$, which would contribute to enhanced sensitivity of DA release to insulin in FR. Conversely, loss of insulin responsiveness in $\mathrm{OB}$ rats is consistent with previous evidence for decreased brain InsR sensitivity induced by weight gain or $\mathrm{OB}$ diets ${ }^{3,10,11}$.

Our ex vivo slice data support the hypothesis that insulin may signal reward as well as satiety. We tested this hypothesis by blocking the effect of endogenous insulin with bilateral InsAb microinjection in the NAc shell during flavour-preference conditioning. Consistent with a role in reward, blocking the effect of insulin decreased preference for the flavour of a paired glucose-containing solution versus the flavour associated with intact insulin signalling. Blocking insulin in the NAc shell also decreased consumption of a paired solution during one-bottle conditioning, whereas mock or control microinjections had no effect on consumption. These data suggest that insulin in the NAc shell plays a role in food preference. Previous studies have shown that intact DA signalling in the NAc is necessary for acquisition of flavour conditioning ${ }^{37,38}$, confirming a role for NAc DA in mediating the reinforcing effects of nutritive solutions. In this light, preference for the glucose solution paired with intact insulin availability argues against a primary effect of insulin on DATmediated DA uptake in the NAc shell, as this would be expected to decrease $[\mathrm{DA}]_{\mathrm{o}}$ and therefore decrease the consumption of the control-paired flavour. Our results are also consistent with those from a previous study in which microinjection of insulin in the NAc shell increased the time the animals were engaged in oral sucrose self-administration, with a borderline increase in sucrose consumption ${ }^{26}$, which was opposite from the expected consequence of increased DA uptake. Overall, these behavioural data are consistent with the predicted influence of insulin on striatal ChIs and enhanced DA release. However, these results do not exclude the involvement of other elements of striatal microcircuitry in the monitored behaviours, given widespread InsR expression throughout striatum ${ }^{1,14}$.

The studies reported here provide the first evidence that insulin plays a role in communicating the caloric value, and therefore the rewarding effects of a meal, which has important implications for the influence of insulin in both underweight and obese subjects. Several studies indicate that the post-ingestive effects of food, regardless of whether taste transduction pathways are intact ${ }^{47}$, increase NAc DA release and positive reinforcement of behaviour $^{37,47}$. Thus, the post-absorptive insulin response may encode the glycaemic yield of a meal and contribute to the reinforcement of food preferences and behaviours that enable consumption. However, extreme changes in circulating insulin levels and central InsR sensitivity could have a role in abnormal, as well as adaptive behaviour. For example, hypoinsulinaemia and compensatory upregulation of InsR sensitivity in FR subjects could be a factor in their disposition to binge ${ }^{48}$. Conversely, central insulin insensitivity in type II diabetes or obesity, mirrored here in $\mathrm{OB}$ rats, could contribute to a diminished sense of reward following ingestion, driving intake of foods with a high glycaemic index as compensation ${ }^{49,50}$. Therefore, either an increase or a decrease in striatal insulin sensitivity could contribute to pathological eating, resulting in binge eating and/or obesity.

Overall, our findings reveal a new role for insulin as a reward signal. Such a role contrasts with its known function as a satiety signal, including recent findings that insulin microinjected into the VTA can decrease hedonic feeding and preference for cues associated with food reward ${ }^{23,24}$. This raises the question of how seemingly opposing roles for insulin in these DA-dependent functions can be reconciled. The answer may be that these effects are complementary, rather than contradictory. The present results indicate that insulin in the striatum communicates the reward value of an ingested meal. A dual role in signalling satiety may simply allow insulin to serve the important purpose of ending a meal, while simultaneously establishing a memory of its nutritional and thus rewarding qualities, thereby reinforcing repetition of the ingestive behaviour.

\section{Methods}

Animal handling. Animal procedures were in accordance with the NIH guidelines and approved by the NYU School of Medicine Animal Care and Use Committee. All animals were on $12 \mathrm{~h}$ light:dark cycle, with lights on from 06:00 to 18:00; ex vivo slices were prepared between 08:00 and 12:00. Mechanistic studies in AL rats and mice were conducted in ex vivo slices from animals housed in pairs, whereas rats were singly housed for all diet group comparisons and for behavioural studies.

Rat diet regimens. Adult male Sprague-Dawley rats (Taconic) were 8-10 weeks old at initiation of diet regimens lasting 21-30 days. Rats were semi-randomly assigned to the diet groups: subjects were ranked by initial weight, then each successive trio of rats was distributed randomly among the diet groups. AL rats had free access to rat chow for the same period as paired rats on FR or OB diets. All rats had free access to water. Food restriction was implemented as previously ${ }^{51}$; briefly, rats received $40-50 \%$ of AL intake of standard rat chow daily until body weight was reduced by $20 \%$, after which food was titrated to maintain this weight. OB rats had free access to rat chow and chocolate Ensure, a highly palatable liquid with moderately high fat and sugar ${ }^{52}$

Forebrain ChAT knockout mice. Mice with a conditional floxed allele of ChAT $\left(C h A T^{\text {flox }}\right)$ were crossed with a $N k \times 2.1^{\text {Cre }}$ transgenic line to produce mice in which ablation of ACh synthesis is restricted to forebrain ${ }^{32}$. Non-mutant transgenic littermates were controls; their genotypes $\mathrm{Cre}^{+} ; \mathrm{ChAT}^{\text {flox } /+}$ and $\mathrm{Cre}^{-}$; $C h A T^{\text {flox/flox }}$ are referred to as 'heterozygotes'. Adult male mice used for slice studies had ad libitum access to chow and water.

Ex vivo slice preparation and physiological solutions. Rats or mice were deeply anaesthetized with $50 \mathrm{mg} \mathrm{kg}^{-1}$ pentobarbital (intraperitoneal (i.p.)) and decapitated. For voltammetry, coronal forebrain slices (300-400- $\mu \mathrm{m}$ thickness) were cut on a Leica VT1200S vibrating blade microtome (Leica Microsystems; Bannockburn, IL) in ice-cold HEPES-buffered artificial CSF (aCSF) containing (in mM): $\mathrm{NaCl}$ (120); $\mathrm{NaHCO}_{3}$ (20); glucose (10); HEPES acid (6.7); $\mathrm{KCl}(5)$; HEPES sodium salt (3.3); $\mathrm{CaCl}_{2}(2)$; and $\mathrm{MgSO}_{4}$ (2), equilibrated with $95 \% \mathrm{O}_{2} / 5 \%$ $\mathrm{CO}_{2}$. Slices were then maintained in this solution at room temperature for $1 \mathrm{~h}$ before experimentation ${ }^{30,32,53}$. For electrophysiology, after anaesthetization, rats were perfused transcardially with ice-cold solution containing (in $\mathrm{mM}$ ): sucrose (225); $\mathrm{KCl}$ (2.5); $\mathrm{CaCl}_{2}(0.5) ; \mathrm{MgCl}_{2}$ (7); $\mathrm{NaHCO}_{3}$ (28); $\mathrm{NaH}_{2} \mathrm{PO}_{4}$ (1.25); glucose 
(7); ascorbate (1); and pyruvate (3), and equilibrated with $95 \% \mathrm{O}_{2} / 5 \% \mathrm{CO}_{2}$. Slices were cut in this solution, then transferred to a recovery chamber in modified aCSF containing (in mM): $\mathrm{NaCl}$ (125); $\mathrm{KCl}(2.5) ; \mathrm{NaH}_{2} \mathrm{PO}_{4}$ (1.25); $\mathrm{NaHCO}_{3}$ (25); $\mathrm{MgCl}_{2}(1) ; \mathrm{CaCl}_{2}$ (2); glucose (25); ascorbate (1); pyruvate (3); and myo-inositol (4), equilibrated with $95 \% \mathrm{O}_{2} / 5 \% \mathrm{CO}_{2}$; this solution was initially at $34{ }^{\circ} \mathrm{C}$, then allowed to cool gradually to room temperature ${ }^{54}$. All voltammetry and physiology experiments were conducted in a submersion recording chamber at $32^{\circ} \mathrm{C}$ that was superfused at $1.5 \mathrm{ml} \mathrm{min}^{-1}$ with aCSF containing (in $\mathrm{mM}$ ): $\mathrm{NaCl}$ (124); $\mathrm{KCl}$ (3.7); $\mathrm{NaHCO}_{3}$ (26); $\mathrm{CaCl}_{2}$ (2.4); $\mathrm{MgSO}_{4}$ (1.3); $\mathrm{KH}_{2} \mathrm{PO}_{4}$ (1.3); and glucose (10), and bovine serum albumin (BSA, $0.05-0.1 \mathrm{mg} \mathrm{ml}^{-1}$ ) equilibrated with $95 \% \mathrm{O}_{2} / 5 \%$ $\mathrm{CO}_{2}$; slices were allowed to equilibrate in this environment for $30 \mathrm{~min}$ before experimentation.

Fast-scan cyclic voltammetry. Evoked DA release studies were conducted using FCV in brain slices ${ }^{32,53}$ prepared from male rats or ChAT forebrain knockout mice and heterozygote controls (5-8 weeks). Studies in ChAT knockout mice were blinded, but rat diet groups had obvious phenotypes that precluded blinding. Voltammetric measurements were made with a Millar Voltammeter (available by special request to Dr Julian Miller at St Bartholomew's and the Royal London School of Medicine and Dentistry, University of London). A conventional triangle waveform was used for FCV, with a scan range of -0.7 to $+1.3 \mathrm{~V}$ (versus $\mathrm{Ag} / \mathrm{AgCl}$ ), scan rate of $800 \mathrm{~V} \mathrm{~s}^{-1}$, and sampling interval of $100 \mathrm{~ms}^{30,32,53}$. Data were acquired using a DigiData 1200B A/D board controlled by Clampex 7.0 software (Molecular Devices). DA release was evoked using a concentric stimulating electrode; stimulus pulse amplitude was $0.4-0.6 \mathrm{~mA}$ and duration was $100 \mu \mathrm{s}^{30,32,53}$. Local single-pulse stimulation was used in NAc core and $\mathrm{CPu}$; however, a brief high-frequency pulse train (five pulses at $100 \mathrm{~Hz}$ ) was used to amplify evoked $[\mathrm{DA}]_{\mathrm{o}}$ in NAc shell. Both stimulus paradigms evoke DA release that is action potential and $\mathrm{Ca}^{2+}$ dependent, unaffected by concurrently released glutamate and $\mathrm{GABA}^{42,55}$, and facilitated by concurrently released $\mathrm{ACh}^{29-34}$. To quantify evoked $[\mathrm{DA}]_{\mathrm{o}}$, electrodes were calibrated with known concentrations of $\mathrm{DA}$ at $32^{\circ} \mathrm{C}$ after each experiment in aCSF and in the presence of each drug used during a given experiment ${ }^{53}$

Voltammetry experiments to assess the effect of insulin on evoked $[\mathrm{DA}]_{\mathrm{o}}$ were obtained using either of two protocols. Initial experiments to determine the time course for the effect of insulin (Sigma, I5523) were performed by monitoring evoked $[\mathrm{DA}]_{\mathrm{o}}$ every $5 \mathrm{~min}$ in a single site. Insulin was applied after consistent evoked $[\mathrm{DA}]_{\mathrm{o}}$ was obtained (typically $4-5$ measurements); the effect of insulin was maximal after 50-60 min, and then evoked $[\mathrm{DA}]_{\mathrm{o}}$ remained at this level for the duration of the experiment (typically $90 \mathrm{~min}$ total insulin exposure; Fig. 1c). Subsequently, the effect of insulin was assessed by recording evoked $[\mathrm{DA}]_{\mathrm{o}}$ at $4-5$ discrete sites in slices $(+1.5 \mathrm{~mm}$ from bregma) in each of three striatal subregions under control conditions (aCSF or aCSF plus drug) and again at the time of maximal insulin effect (sampling over 60-80 min), then these samples were averaged for each subregion. The effect of insulin diminished with time after slice preparation; to minimize time ex vivo and to optimize animal use, typically, two slices from a given animal were tested in the recording chamber at the same time. Drugs used to challenge the effect of insulin were applied $15 \mathrm{~min}$ before insulin via superfusing aCSF, including HNMPA trisacetoxymethyl ester (HNMPA-AM ${ }_{3}$, Enzo Life Sciences), S961 (Novo Nordisk), LY294002 (Sigma), picropodophyllotoxin (PPP; Tocris), mecamylamine (Tocris) and DH $\beta E$ (Tocris). As described in Results, possible altered sensitivity of nicotinic ACh receptors among diet groups was tested by comparing the ratio of peak $[\mathrm{DA}]_{\mathrm{o}}$ evoked by $5 \mathrm{p}$ $(100 \mathrm{~Hz})$ with that evoked by $1 \mathrm{p}$ evoked $(5 \mathrm{p}: 1 \mathrm{p} \text { ratio })^{30,31}$ in NAc core in the presence of $0-500 \mathrm{nM}$ nicotine (Sigma).

\section{Determination of $\boldsymbol{V}_{\max }$ from evoked [DA]} evaluate insulin-induced changes in DAT-mediated DA uptake, the initial portion of the falling phase of evoked [DA] equation to extract $V_{\max }$ (maximal uptake rate constant) ${ }^{56}$. $K_{\mathrm{m}}$ (which is inversely related to the affinity of the DAT for DA) was fixed at $0.2 \mu \mathrm{M}$ and is known to be similar across striatal subregions ${ }^{57}$ and unaffected by insulin (see Supplementary Fig. 4 caption).

Whole-cell recording. Brain slices were prepared from 29- to 35-day-old male rats; recording conditions were identical to those used in DA release studies. Whole-cell current-clamp recordings used conventional methods ${ }^{54}$. Striatal ChIs were visualized using an Olympus BX51WI microscope (Olympus America, Center Valley, PA) with infrared differential-interference contrast optics and a $\times 40$ water-immersion objective. The pipette solution contained (in $\mathrm{mM}$ ): K-gluconate (129); KCl (11); HEPES (10); $\mathrm{MgCl}_{2}$ (2); EGTA (1); $\mathrm{Na}_{2}$-ATP (2); $\mathrm{Na}_{3}$-GTP (0.3); and adjusted to $\mathrm{pH} 7.2-7.3$ with $\mathrm{KOH}$. For recorded neurons to be assessed for ChAT immunoreactivity, $0.3 \%$ biocytin was included in the pipette solution and the neurons recorded briefly ( $\sim 5 \mathrm{~min})$ to minimize dilution of intracellular contents. Pipette resistance was $\sim 3-5 \mathrm{M} \Omega$. Recordings were obtained using an Axopatch 200B amplifier (Molecular Devices, Sunnyvale CA) and low-pass filtered at $2 \mathrm{kHz}$. ChIs were identified by established electrophysiological criteria ${ }^{28}$; most were tonically active initially, but activity diminished variably after patching. However, responsiveness to current injection was generally robust and consistent over time, and was therefore used to investigate the effect of insulin on ChI excitability (see Results). In experiments to examine the role of InsRs and IGF-1Rs in this response, either HNMPA or PPP was applied for at least 20 min before a $\mathrm{ChI}$ was patched. Maximal effects of insulin alone were typically observed after $\sim 16$ min of exposure, although in some cells, the increase was not maximal until $50 \mathrm{~min}$ or longer. Moreover, in four of six neurons recorded in PPP, insulin caused an initial decrease in spike number before recovering to and exceeding starting spike number. Consequently, in all experiments, the effect of insulin was quantified by comparing the maximum effect on spike number with the number of spikes evoked immediately before insulin application. The apparent difference in the time to reach peak effect could reflect a number of factors, including the depth of the recorded cell in the slice. Evoked action potentials were also recorded in ChIs in the absence of insulin at comparable time points.

High-performance liquid chromatography. The DA content of rat striatal slices (400- $\mu \mathrm{m}$ thickness) was determined using high-performance liquid chromatography with electrochemical detection ${ }^{58}$. Slice pairs were equilibrated for $30 \mathrm{~min}$ at $32{ }^{\circ} \mathrm{C}$ in aCSF, and then one slice per pair was incubated for an additional $60 \mathrm{~min}$ at $32^{\circ} \mathrm{C}$ in aCSF while the other was incubated in aCSF with 10 or $30 \mathrm{nM}$ insulin. For diet group comparisons, striatal tissue was collected between 30-60 min post-recovery. Following incubation, excess aCSF was carefully removed from slices, a sample of striatal tissue $(7-10 \mathrm{mg})$ was weighed, frozen on dry ice and then stored at then stored at $-80^{\circ} \mathrm{C}$. On the day of analysis, samples were sonicated in ice-cold, eluent, deoxygenated with $\operatorname{argon}^{58}$, spun in a microcentrifuge for $2 \mathrm{~min}$, and the supernatant injected directly onto the HPLC column (BAS, West Lafayette, IN); the detector was a glassy carbon electrode set at $0.7 \mathrm{~V}$ versus $\mathrm{Ag} /$ $\mathrm{AgCl}$.

Immunohistochemistry. For immunohistochemical labelling, rats were anaesthetized with sodium pentobarbital $\left(50 \mathrm{mg} \mathrm{kg}^{-1}\right.$, i.p.), then perfused transcardially with PBS ( $154 \mathrm{mM} \mathrm{NaCl}$ in $10 \mathrm{mM}$ phosphate buffer, $\mathrm{pH} 7.2)$ followed by $4 \%$ paraformaldehyde in this PBS; brains were removed and coronal sections $(20 \mu \mathrm{m})$ were cut and processed conventionally ${ }^{27,59}$. Immunofluorescence images were obtained with a Nikon PM 800 confocal microscope equipped with a digital camera controlled by Spot software (Diagnostic Instruments Inc.) and using a $\times 100$ objective (numerical aperture $=1.4$ ) or with a Zeiss LSM 510 confocal microscope using a $\times 63$ objective (numerical aperture $=1.2$ ). The lasers were Argon $(488 \mathrm{~nm}), \mathrm{He} / \mathrm{Ne}(543 \mathrm{~nm})$ and $\mathrm{He} / \mathrm{Ne}(633 \mathrm{~nm})$. Appropriate filters for each laser were selected by the confocal microscope software. Pinhole size varied with the objective used and section thickness selected in $z$-stack generation; we chose the optimum pinhole value indicated by the software (typically $30 \mu \mathrm{m}$ ). Digital files were analysed with deconvolution software (AutoQuant Imaging), with final images processed using Adobe Photoshop 7.0. All images were adjusted for brightness and contrast; such adjustments were made uniformly to all parts of the image. Striatal DA axons were identified using two TH antibodies: polyclonal AB152 rabbit anti-TH (1:800) and monoclonal MAB318 mouse anti-TH (1:500) (both from Chemicon). Three InsR antibodies were used: sc57342 and sc-09 (1:100; Santa Cruz), and PP5 (a gift from Pfizer). The specificity of each has been demonstrated previously ${ }^{60,61}$, and was confirmed in the present studies by the absence of immunolabelling with antibodies sc-57342 or PP5 in the presence of the corresponding blocking peptide. ChAT antibody was AB144 (1:200; Millipore), and biotin was from Vector (1:200). Secondary antibodies used were donkey anti-rabbit Alexa 488 (Invitrogen), or donkey anti-rabbit Cy2 (Jackson Laboratory, Bar Harbor, $\mathrm{ME}$ ), donkey anti-goat Cy3 (Jackson) and donkey anti-mouse Cy5 (Jackson).

To evaluate co-localization of InsRs in TH + axons, we used methods described previously to identify the presence of Kir6.2, the pore-forming subunit of ATP-sensitive $\mathrm{K}^{+}$channels in DA axons ${ }^{27}$. Puncta representing InsRs were distributed throughout adjusted images, indicating that superimposition with $\mathrm{TH}$ immunoreactivity may occur to some degree by chance. To test this assumption, we counted InsR/TH superimpositions in 42 independent fields in three NAc immunolabelled sections from two rats. The InsR digital files were then rotated $90^{\circ}$ clockwise and the counts repeated; rotation decreased the number of InsR puncta that co-localized with TH in most fields (see Results). The decrease in the number of superimpositions with rotation ${ }^{27}$ indicated the proportion of InsR puncta in each striatal field associated with DA axons.

Blood glucose and insulin ELISA. Trunk blood was collected at time of decapitation for slice studies. Blood glucose was determined immediately with a standard blood glucose monitor. For insulin, additional blood was collected in EDTAcontaining tubes and centrifuged at $1,500 \mathrm{~g}$ for $15 \mathrm{~min}$; supernatant (plasma) was collected and stored at $-80^{\circ} \mathrm{C}$ until processing with an ALPCO Rat Insulin ELISA kit.

Cannula placement and histological verification. Forty one adult male Sprague-Dawley rats (Taconic and Charles River) initially weighing $350-425 \mathrm{~g}$ were anaesthetized with ketamine $\left(100 \mathrm{mg} \mathrm{kg}^{-1}\right.$, i.p.) and xylazine $\left(10 \mathrm{mg} \mathrm{kg}^{-1}\right.$, i.p.) and stereotaxically implanted with two chronically indwelling guide cannulae (26 gauge) placed bilaterally $2.0 \mathrm{~mm}$ dorsal to infusion sites in the NAc medial shell $^{62}(1.6 \mathrm{~mm}$ anterior to bregma; $2.1 \mathrm{~mm}$ lateral to the sagittal suture, tips angled $8^{\circ}$ towards the midline, $5.8 \mathrm{~mm}$ ventral to skull surface). Rats were given banamine (2.0 $\mathrm{mg} \mathrm{kg}^{-1}$, subcutaneous) as a post-surgical analgesic following recovery from 
anaesthesia and the morning after. One week after surgery, rats were placed on FR (described above) and maintained at $80 \%$ of their post-surgical recovery weight for the remainder of the study. Cannula placement was determined histologically after completion of behavioural testing. Each rat was killed with $\mathrm{CO}_{2}$, decapitated and the brain removed and fixed in $10 \%$ buffered formalin for $>48 \mathrm{~h}$. Frozen coronal sections (40- $\mu \mathrm{m}$ thickness) were cut on a Reichert-Jung Cryostat, thaw mounted on gelatin-coated glass slides, and stained with cresyl violet. Data from a given rat were used only if both cannulae were within the medial NAc shell ${ }^{62}$ (including the shell/core or shell/olfactory tubercle border) (Supplementary Fig. 5); based on these criteria, two rats were excluded from the final analysis.

Flavour-preference conditioning pre-exposure. Rats received one overnight (in home cage) and six 30-min-per-day sessions of pre-exposure (in testing chambers) to $0.2 \%$ sodium saccharin (Sigma) in water with a 48 -h interval between sessions. Rats then received two 5-min-per-day sessions of exposure to $0.2 \%$ sodium saccharin in $0.05 \%$ unsweetened grape or cherry Kool-Aid (Kraft Foods) in water. For the first Kool-Aid pre-exposure session, half of the rats received cherryflavoured solution, and the other half received grape-flavoured solution. The flavours were reversed on the second Kool-Aid pre-exposure session to ensure that all rats sampled each flavour. Intake was measured for all pre-exposure sessions. Testing chambers were clear plastic cages with fresh bedding. For all pre-exposure sessions, rats had access to the same solution on both sides of the chamber. Except for the overnight pre-exposure session, all sessions were conducted in a behavioural procedure room, with a 30-min habituation period before any training or testing.

One-bottle conditioning. Previous studies have shown that microinjection of InsAb into ventromedial hypothalamus can block the effect of insulin on feeding behaviour and glucagon secretion ${ }^{63,64}$. Here we used this approach to assess a possible role of insulin in the reinforcement of food choice. Rats were semirandomly assigned based on average pre-exposure intake volume into two groups, control or experimental (InsAb). In the control group, rats received vehicle (microinjection PBS; $137 \mathrm{mM} \mathrm{NaCl}$ and $2.7 \mathrm{mM} \mathrm{KCl}$ in $10 \mathrm{mM}$ phosphate buffer) or IgG (Abcam ab81032; $0.5 \mu \mathrm{gl}^{-1}$ in PBS, as received) microinjection in NAc shell before consuming one of the two flavoured solutions, and a mock microinjection before consuming the other flavoured solution. In the experimental group, rats received NAc shell microinjection of InsAb (Abcam ab46707; $0.5 \mu \mathrm{l}$ of $1 \mu \mathrm{g} \mu \mathrm{l}^{-1}$ in PBS, as received) before exposure to one flavoured solution, and mock microinjection prior exposure to the other. Two sets of subjects with alternation between fluid microinjection and mock microinjection were used, so that the total number of microinjections was limited to four, thereby minimizing possible tissue damage and loss of sensitivity at the microinjection site ${ }^{65}$. For fluid microinjection, control solution or InsAb was loaded into two $30-\mathrm{cm}$ lengths of PE-50 tubing attached at one end to $5 \mu \mathrm{l}$ Hamilton syringes filled with distilled water and at the other end to 31-gauge injector cannulae, which extended $2.0 \mathrm{~mm}$ beyond the implanted guides. The $0.5 \mu$ infusion volumes were delivered over $90 \mathrm{~s}$ at a rate of $0.005 \mathrm{\mu l} \mathrm{s}^{-1}$; the injector was left in place for $\sim 60 \mathrm{~s}$ to allow time for diffusion, then the injector was replaced with the stylet.

Rats were transferred directly to the behavioural chambers within 2 min of completion of the microinjection or mock microinjection. Conditioning solutions contained $0.2 \%$ sodium saccharin, $0.05 \%$ unsweetened grape or cherry Kool-Aid, and $0.8 \%$ glucose. Solution access was limited to $30 \mathrm{~min}$ per session. Paired flavour and side of the chamber with drinking access were semi-randomly assigned and counterbalanced in each group. The interval between microinjections was at least $72 \mathrm{~h}$, alternating between infusion and mock sessions for a total of eight conditioning sessions.

Two-bottle preference test. Forty-eight hours after the last conditioning session, rats were placed in testing chambers with simultaneous access to both conditioning flavours; solutions were $0.2 \%$ sodium saccharin in $0.05 \%$ grape or cherry Kool-Aid, without glucose. Testing occurred over 2 days $(60 \mathrm{~min}$ per day). The position of the drinking tube containing mock-paired or infusion-paired solution was alternated to ensure that each rat was tested for consumption of each solution on both sides of the cage. Intake of each flavoured solution was averaged for the two test days to determine preference.

[ ${ }^{3} \mathbf{H}$ ]DA uptake in striatal synaptosomes to assess InsAb efficacy. Striatal synaptosomes ${ }^{21,66}$ were prepared from AL rats (male, 350-400 g), with NAc (shell and core) and $\mathrm{CPu}$ dissected and prepared separately. Tissue from each region was homogenized in 15 volumes of an ice-cold $0.32 \mathrm{M}$ sucrose solution in a glass homogenizer with motor-driven Teflon pestle; after rinsing and centrifugation, the final pellet was re-suspended in ice-cold $0.32 \mathrm{M}$ sucrose ${ }^{21,66}$. Before initiating the $\left[{ }^{3} \mathrm{H}\right] \mathrm{DA}$ uptake assay ${ }^{66}$, synaptosomal aliquots in a total volume of $180 \mu \mathrm{l}$ of uptake buffer were incubated in a shaker for $15 \mathrm{~min}$ at $30^{\circ} \mathrm{C}$ in the presence or absence of $30 \mathrm{nM}$ insulin, in vehicle (PBS) or in InsAb (final dilution 1:500), in IgG (final dilution 1:500) or in vehicle. Uptake buffer contained (in $\mathrm{mM}$ ): $\mathrm{NaCl}$ (122); $\mathrm{Na}_{2} \mathrm{HPO}_{4}$ (3); $\mathrm{NaH}_{2} \mathrm{PO}_{4}$ (15); $\mathrm{KCl}$ (5); $\mathrm{MgSO}_{4}$ (1.2); glucose (10), $\mathrm{CaCl}_{2}(1)$; nialamide (0.01); tropolone (0.1); and ascorbic acid (0.001), $\mathrm{pH}$ 7.4. Uptake of $\left[{ }^{3} \mathrm{H}\right] \mathrm{DA}$ was initiated by rapidly dispensing $20 \mu \mathrm{l}$ of each synaptosomal suspension into the 96-well plates with varying concentrations of DA $(0.003-1.0 \mu \mathrm{M})$ and $\left[{ }^{3} \mathrm{H}\right] \mathrm{DA}(5 \mathrm{nM})$; after $5 \mathrm{~min}$ in a plate-shaker at $25^{\circ} \mathrm{C}$, uptake was terminated by cold, rapid vacuum filtration ${ }^{66}$. Counts per well were converted to pmoles, then corrected to $\mathrm{mg}$ of total protein per minute. All assays were performed in triplicate and repeated at least four times; $V_{\max }$ and $K_{\mathrm{m}}$ were calculated using Biosoft Kell Radlig software (Cambridge, UK).

Statistical analysis. Data are given as means \pm s.e.m.; significance was assessed using paired or unpaired Student's $t$-tests or ANOVA, unless indicated otherwise. For voltammetry data, $n$ is number of recording sites, given that site-to-site variability within a striatal subregion is greater than inter-animal or inter-slice variability $30,32,55,56$; animal number is noted for each data set. The $\mathrm{EC}_{50}$ for the effect of insulin and nicotine on peak-evoked $[\mathrm{DA}]_{\mathrm{o}}$ was calculated using Prism 6.0 (GraphPad Software Inc., La Jolla, CA). For electrophysiological data, statistical significance was assessed using paired $t$-tests or a Wilcoxon test in Prism 6.0, or a mixed two-way ANOVA in SAS 9.3 (SAS Institute Inc., Cary, NC). For evaluation of insulin involvement in flavour-preference conditioning, two full studies were completed using protocols that were identical with the exception of the vehicle treatment used. In the first study, 10 rats received vehicle infusions of PBS and 9 received infusions of InsAB. In the second study, 10 rats received vehicle infusions of IgG and 10 received infusions of InsAb. There was no significant difference between the two vehicle groups (PBS or IgG) during infusion-conditioning sessions $\left(F_{19}=0.619\right.$, mixed two-way ANOVA $)$ with repeated measures on infusionconditioning session) or at test $\left(F_{19}=0.012\right.$, two-way mixed ANOVA with repeated measures on flavour). Consequently, the two experiments were combined for analysis. For this analysis, a $2 \times 4$ mixed ANOVA (with repeated measures on infusion-conditioning day) was used to determine the effects of microinjection treatment during conditioning, followed by protected $t$-tests (one tailed to determine in which conditioning sessions microinjection treatment decreased intake volume). The same analysis was completed for mock conditioning sessions. To determine the effect of conditioning treatment during a two-bottle flavourpreference test, data were analysed using a mixed two-way ANOVA (with repeated measures on flavour), followed by protected $t$-tests (one tailed to test the hypothesis that InsAb would decrease preference).

\section{References}

1. Schulingkamp, R. J., Pagano, T. C., Hung, D. \& Raffa, R. B. Insulin receptors and insulin action in the brain: review and clinical implications. Neurosci. Biobehav. Rev. 24, 855-872 (2000).

2. Gerozissis, K. Brain insulin, energy and glucose homeostasis; genes, environment and metabolic pathologies. Eur. J. Pharmacol. 585, 38-49 (2008).

3. Vogt, M. C. \& Bruning, J. C. CNS insulin signaling in the control of energy homeostasis and glucose metabolism-from embryo to old age. Trends Endocrinol. Metab. 24, 76-84 (2013).

4. Havrankova, J., Schmechel, D., Roth, J. \& Brownstein, M. Identification of insulin in rat brain. Proc. Natl Acad. Sci. USA 75, 5737-5741 (1978).

5. King, G. L. \& Johnson, S. Receptor-mediated transport of insulin across endothelial cells. Science 227, 1583-1586 (1985).

6. Strubbe, J. H., Porte, Jr D. \& Woods, S. C. Insulin responses and glucose levels in plasma and cerebrospinal fluid during fasting and refeeding in the rat. Physiol. Behav. 44, 205-208 (1988)

7. Banks, W. A. \& Kastin, A. J. Differential permeability of the blood-brain barrie to two pancreatic peptides: insulin and amylin. Peptides 19, 883-889 (1998).

8. Banks, W. A. The source of cerebral insulin. Eur. J. Pharmacol. 490, 5-12 (2004).

9. Nemoto, T. et al. New insights concerning insulin synthesis and its secretion in rat hippocampus and cerebral cortex: amyloid- $\beta 1-42$-induced reduction of proinsulin level via glycogen synthase kinase-3ß. Cell Signal. 26, 253-259 (2014).

10. De Souza, C. T. et al. Consumption of a fat-rich diet activates a proinflammatory response and induces insulin resistance in the hypothalamus. Endocrinology 146, 4192-4199 (2005).

11. Anthony, K. et al. Attenuation of insulin-evoked responses in brain networks controlling appetite and reward in insulin resistance: the cerebral basis for impaired control of food intake in metabolic syndrome? Diabetes 55, 2986-2992 (2006).

12. Kelley, A. E. \& Berridge, K. C. The neuroscience of natural rewards: relevance to addictive drugs. J. Neurosci. 22, 3306-3311 (2002).

13. Koob, G. F. \& Volkow, N. D. Neurocircuitry of addiction. Neuropsychopharmacology 35, 217-238 (2010).

14. Werther, G. A. et al. Localization and characterization of insulin receptors in rat brain and pituitary gland using in vitro autoradiography and computerized densitometry. Endocrinology 121, 1562-1570 (1987).

15. Figlewicz, D. P., Evans, S. B., Murphy, J., Hoen, M. \& Baskin, D. G. Expression of receptors for insulin and leptin in ventral tegmental area/substantia nigra (VTA/SN) of the rat. Brain Res. 964, 107-115 (2003).

16. Daws, L. C. et al. Insulin signaling and addiction. Neuropharmacology 61, 1123-1128 (2011).

17. Figlewicz, D. P. \& Sipols, A. J. Energy regulatory signals and food reward. Pharmacol. Biochem. Behav. 97, 15-24 (2010). 
18. Patterson, T. A. et al. Food deprivation decreases mRNA and activity of the rat dopamine transporter. Neuroendocrinology 68, 11-20 (1998).

19. Carvelli, L. et al. PI 3-kinase regulation of dopamine uptake. J. Neurochem. 81, 859-869 (2002).

20. Williams, J. M. et al. Hypoinsulinemia regulates amphetamine-induced reverse transport of dopamine. PLoS Biol. 5, e274 (2007).

21. Zhen, J., Reith, M. E. A. \& Carr, K. D. Chronic food restriction and dopamine transporter function in rat striatum. Brain Res. 1082, 98-101 (2006).

22. Schoffelmeer, A. N. et al. Insulin modulates cocaine-sensitive monoamine transporter function and impulsive behavior. J. Neurosci. 31, 1284-1291 (2011).

23. Mebel, D. M., Wong, J. C., Dong, Y. J. \& Borgland, S. L. Insulin in the ventral tegmental area reduces hedonic feeding and suppresses dopamine concentration via increased reuptake. Eur. J. Neurosci. 36, 2336-2346 (2012).

24. Labouebe, G. et al. Insulin induces long-term depression of ventral tegmental area dopamine neurons via endocannabinoids. Nat. Neurosci. 16, 300-308 (2013).

25. Konner, A. C. et al. Role for insulin signaling in catecholaminergic neurons in control of energy homeostasis. Cell Metab. 13, 720-728 (2011).

26. Figlewicz, D. P., Bennett, J. L., Aliakbari, S., Zavosh, A. \& Sipols, A. J. Insulin acts at different CNS sites to decrease acute sucrose intake and sucrose self-administration in rats. Am. J. Physiol. Regul. Integr. Comp. Physiol. 295, R388-R394 (2008).

27. Patel, J. C., Witkovsky, P., Coetzee, W. A. \& Rice, M. E. Subsecond regulation of striatal dopamine release by pre-synaptic $\mathrm{K}_{\mathrm{ATP}}$ channels. J. Neurochem. 118, 721-736 (2011).

28. Tepper, J. M. \& Bolam, J. P. Functional diversity and specificity of neostriatal interneurons. Curr. Opin. Neurobiol. 14, 685-692 (2004).

29. Zhou, F. M., Liang, Y. \& Dani, J. A. Endogenous nicotinic cholinergic activity regulates dopamine release in the striatum. Nat. Neurosci. 4, 1224-1229 (2001).

30. Rice, M. E. \& Cragg, S. J. Nicotine amplifies reward-related dopamine signals in striatum. Nat. Neurosci. 7, 583-584 (2004).

31. Zhang, H. \& Sulzer, D. Frequency-dependent modulation of dopamine release by nicotine. Nat. Neurosci. 7, 581-582 (2004).

32. Patel, J. C., Rossignol, E., Rice, M. E. \& Machold, R. P. Opposing regulation of striatal dopamine release and exploratory motor behavior by forebrain and brainstem cholinergic inputs. Nat. Commun. 3, 1172 (2012).

33. Threlfell, S. et al. Striatal dopamine release is triggered by synchronous activity in cholinergic interneurons. Neuron 75, 58-64 (2012).

34. Cachope, R. et al. Selective activation of cholinergic interneurons enhances accumbal phasic dopamine release: setting the tone for reward processing. Cell Rep. 2, 1-9 (2012).

35. Jones, I. W., Bolam, J. P. \& Wonnacott, S. Presynaptic localisation of the nicotinic acetylcholine receptor beta2 subunit immunoreactivity in rat nigrostriatal dopaminergic neurones. J. Comp. Neurol. 439, 235-247 (2001).

36. Higley, M. J. et al. Cholinergic interneurons mediate fast VGluT3-dependent glutamatergic transmission in the striatum. PLoS ONE 6, e19155 (2011).

37. Touzani, K., Bodnar, R. \& Sclafani, A. Activation of dopamine D1-like receptors in nucleus accumbens is critical for the acquisition, but not the expression, of nutrient-conditioned flavor preferences in rats. Eur. J. Neurosci. 27, 1525-1533 (2008).

38. Sclafani, A., Touzani, K. \& Bodnar, R. J. Dopamine and learned food preferences. Physiol. Behav. 104, 64-68 (2011).

39. Mayer, C. M. \& Belsham, D. D. Central insulin signaling is attenuated by longterm insulin exposure via insulin receptor substrate-1 serine phosphorylation, proteasomal degradation, and lysosomal insulin receptor degradation. Endocrinology 151, 75-84 (2010).

40. Rice, M. E., Patel, J. C. \& Cragg, S. J. Dopamine release in the basal ganglia. Neuroscience 198, 112-137 (2011).

41. Smith, Y., Surmeier, D. J., Redgrave, P. \& Kimura, M. Thalamic contributions to basal ganglia-related behavioral switching and reinforcement. J. Neurosci. 31, 16102-16106 (2011)

42. Threlfell, S. et al. Striatal muscarinic receptors promote activity dependence of dopamine transmission via distinct receptor subtypes on cholinergic interneurons in ventral versus dorsal striatum. J. Neurosci. 30, 3398-3408 (2010).

43. Hoebel, B. G., Avena, N. M. \& Rada, P. Accumbens dopamine-acetylcholine balance in approach and avoidance. Curr. Opin. Pharmacol. 7, 617-627 (2007).

44. Pothos, E. N., Creese, I. \& Hoebel, B. G. Restricted eating with weight loss selectively decreases extracellular dopamine in the nucleus accumbens and alters dopamine response to amphetamine, morphine, and food intake. J. Neurosci. 15, 6640-6650 (1995).

45. Geiger, B. M. et al. Deficits of mesolimbic dopamine neurotransmission in rat dietary obesity. Neuroscience 159, 1193-1199 (2009).

46. Morris, J. K. et al. Insulin resistance impairs nigrostriatal dopamine function. Exp. Neurol. 231, 171-180 (2011).

47. De Araujo, I. E. et al. Food reward in the absence of taste receptor signaling. Neuron 57, 930-941 (2008).

48. Stice, E., Spoor, S., Bohon, C. \& Small, D. M. Relation between obesity and blunted striatal response to food is moderated by TaqIA A1 allele. Science 322, 449-452 (2008)
49. Wang, G. J. et al. Brain dopamine and obesity. Lancet 357, 354-357 (2001).

50. Johnson, P. M. \& Kenny, P. J. Dopamine D2 receptors in addiction-like reward dysfunction and compulsive eating in obese rats. Nat. Neurosci. 13, 635-641 (2010).

51. Carr, K. D., Kim, G.-Y. \& Cabeza de Vaca, S. Rewarding and locomotoractivating effects of direct dopamine receptor agonists are augmented by chronic food restriction in rats. Psychopharmacology (Berl.) 154, 420-428 (2001).

52. Levin, B. E. \& Keesey, R. E. Defense of differing body weight set points in diet-induced obese and resistant rats. Am. J. Physiol. 274, R412-R419 (1998).

53. Patel, J. C. \& Rice, M. E. Monitoring axonal and somatodendritic dopamine release using fast-scan cyclic voltammetry in brain slices. Methods Mol. Biol. 96, 243-273 (2013).

54. Lee, C. R., Witkovsky, P. \& Rice, M. E. Regulation of substantia nigra pars reticulata GABAergic neuron activity by $\mathrm{H}_{2} \mathrm{O}_{2}$ via flufenamic acid-sensitive channels and $\mathrm{K}_{\mathrm{ATP}}$ channels. Front. Syst. Neurosci. 5, 14 (2011).

55. Chen, B. T., Moran, K. A., Avshalumov, M. V. \& Rice, M. E. Limited regulation of somatodendritic dopamine release by voltage-sensitive $\mathrm{Ca}^{2+}$ channels contrasted with strong regulation of axonal dopamine release. J. Neurochem. 96, 645-655 (2006).

56. Li, X. et al. Enhanced striatal dopamine transmission and motor performance with LRRK2 overexpression in mice is eliminated by familial Parkinson's disease mutation G2019S. J. Neurosci. 30, 1788-1797 (2010).

57. Wu, Q., Reith, M. E. A., Wightman, R. M., Kawagoe, K. T. \& Garris, P. A. Determination of release and uptake parameters from electrically evoked dopamine dynamics measured by real-time voltammetry. J. Neurosci. Methods 112, 119-133 (2001).

58. Chen, B. T., Avshalumov, M. V. \& Rice, M. E. $\mathrm{H}_{2} \mathrm{O}_{2}$ is a novel, endogenous modulator of synaptic dopamine release. J. Neurophysiol. 85, 2468-2476 (2001)

59. Witkovsky, P., Patel, J. C., Lee, C. R. \& Rice, M. E. Immunocytochemical identification of proteins involved in dopamine release from the somatodendritic compartment of nigral dopaminergic neurons. Neuroscience 164, 488-496 (2009).

60. Sugimoto, K. et al. Insulin receptor in rat peripheral nerve: its location and alternatively spliced isoforms. Diabetes Metab. Res. Rev. 16, 354-363 (2000).

61. Sanchez-Alavez, M. et al. Insulin causes hyperthermia by direct inhibition of warm-sensitive neurons. Diabetes 59, 43-50 (2010).

62. Paxinos, G. \& Watson, C. The Rat Brain in Stereotaxic Coordinates 6th edn (Academic, 2007).

63. Strubbe, J. H. \& Mein, C. G. Increased feeding in response to bilateral injection of insulin antibodies in the VMH. Physiol Behav. 19, 309-313 (1977).

64. Paranjape, S. A. et al. Influence of insulin in the ventromedial hypothalamus on pancreatic glucagon secretion in vivo. Diabetes 59, 1521-1527 (2010).

65. Wise, R. A. \& Hoffman, D. C. Localization of drug reward mechanisms by intracranial injections. Synapse 10, 247-263 (1992).

66. Zhen, J., Maiti, S., Chen, N., Dutta, A. K. \& Reith, M. E. A. Interaction between a hydroxypiperidine analogue of 4-(2-benzhydryloxy-ethyl)-1(4-fluorobenzyl)piperidine and aspartate 68 in the human dopamine transporter. Eur. J. Pharmacol. 506, 17-26 (2004).

\section{Acknowledgements}

These studies were supported by NIH grants DA033811 (M.E.R., K.D.C. and M.E.A.R.), NS036362 (M.E.R.), DA03956 (K.D.C.) and a NARSAD Independent Investigator Award (K.D.C.). S961 was a generous gift from Dr Lauge Schaffer, Novo Nordisk. PP5 antibody was a generous gift from Pfizer. We thank Dr Charles Nicholson, NYU School of Medicine for software to extract $V_{\max }$ values from FCV data.

\section{Author contributions}

M.A.S., M.E.R. and K.D.C. designed the overall study and drafted the manuscript; all authors contributed to the final manuscript text; M.A.S. conducted voltammetry experiments and data analysis, with contributions from L.B. and J.C.P.; J.C.P. contributed to the design of voltammetry experiments and provided software and analysed $V_{\max }$ data; P.W. obtained all immunohistochemistry images and provided quantitative analysis of these data; C.R.L. designed electrophysiology protocols and obtained biocytin-filled neurons; C.R.L. and J.C.P. performed electrophysiology studies and conducted all associated data analysis; R.P.M. developed and provided forebrain ChAT KO mice; C.A.W. and M.A.S. designed behavioural studies in consultation with K.D.C. and S.C.d.V.; these were conducted primarily by C.A.W.; S.C.d.V. also contributed to statistical analysis of the behavioural data; K.T.J. and M.E.A.R. designed and analysed DA uptake experiments in synaptosomes to assess efficacy of InsAb; K.T.J. conducted the experiments.

\section{Additional information}

Supplementary Information accompanies this paper at http://www.nature.com/ naturecommunications

Competing financial interests: The authors declare no competing financial interests. 
Reprints and permission information is available online at http://npg.nature.com/ reprintsandpermissions/

How to cite this article: Stouffer, M. A. et al. Insulin enhances striatal dopamine release by activating cholinergic interneurons and thereby signals reward. Nat. Commun. 6:8543 doi: $10.1038 /$ ncomms 9543 (2015). (c) (i) This work is licensed under a Creative Commons Attribution 4.0 International License. The images or other third party material in this article are included in the article's Creative Commons license, unless indicated otherwise in the credit line; if the material is not included under the Creative Commons license, users will need to obtain permission from the license holder to reproduce the material. To view a copy of this license, visit http://creativecommons.org/licenses/by/4.0/ 